\title{
SLEEP MEDICINE CONTENT IN DENTAL HYGIENE EDUCATION
}

\author{
Brittany Minichbauer
}

A thesis submitted to the faculty at the University of North Carolina at Chapel Hill in partial fulfillment of the requirement for the degree of Master of Dental Hygiene Education in the School of Dentistry.

\section{Chapel Hill}

2014

Approved by:

Rose Sheats

Rebecca Wilder

Ceib Phillips

Gregory Essick 
(C) 2014

Brittany Minichbauer

ALL RIGHTS RESERVED 


\section{ABSTRACT \\ Brittany Minichbauer: Sleep Medicine in Dental Hygiene Education (Under the direction of Gregory Essick)}

Purpose/Objectives: According to the National Sleep Foundation, 70 million Americans chronically suffer from approximately 60 medically recognized sleep disorders. Clinicians are unaware of these disorders and many individuals remain undiagnosed. The purpose of this study was to assess the amount of sleep medicine content in dental hygiene programs across the United States (US). Methods: A survey was emailed to all 334 accredited US dental hygiene programs. Follow-up emails and phone calls were made to non-responding programs. Results: Thirty-five percent of the programs responded. The mean number of hours devoted to sleep medicine was 1.55 hours $(\mathrm{sd}=1.37)$. Seventy four percent of the responding programs reported spending time on sleep bruxism (mean $=1.38$ hours, $\mathrm{sd}=0.85$ ); however only $39 \%$ reported spending time on other topics such as snoring and obstructive sleep apnea (mean=1.39 hours, $\mathrm{sd}=0.72$ ).

Conclusion: Sleep medicine is included in the majority of US dental hygiene programs, however the content is limited and focused on sleep bruxism. 


\section{TABLE OF CONTENTS}

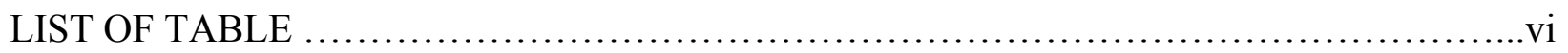

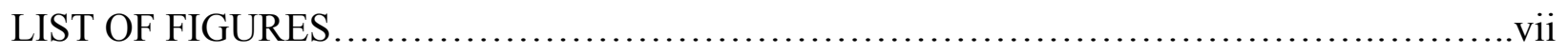

LIST OF ABBREVIATIONS.............................................................viii

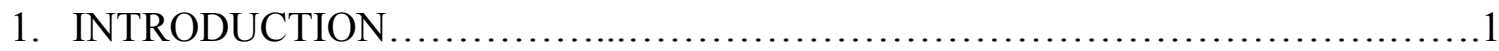

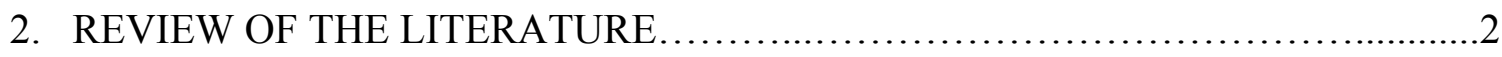

2.1 Sleep-related Movement Disorders.........................................

2.2 Sleep-related Breathing Disorders.............................................

2.3 Other Sleep Disorders...................................................

2.4 Sleep Medicine and overall health..............................................

2.5 Treatments for Sleep Disorders.............................................

2.6 Professional Education about Sleep Disorders................................6

3. INTRODUCTION AND LITERATURE REVIEW ..................................10

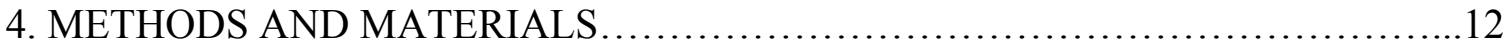

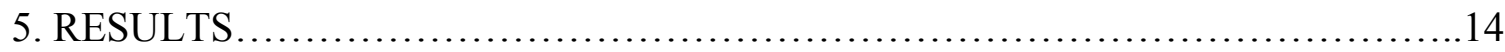

Demographics of respondents........................................... 14

Didactic curriculum............................................................

Sleep bruxism................................................... 15 
All other topics in sleep medicine.................................15

Sleep disordered breathing...................................16

Oral appliances................................................ 16

Laboratory instruction............................................. 17

Course and faculty............................................... 17

Opinions.......................................................... 18

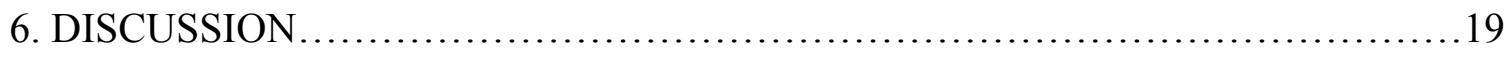

SM in didactic curriculum and laboratory settings........................ 19

Regional and institutional type representation...........................20

Limitations of the study ...............................................

Significance of findings...........................................22

Relevance to dental hygienists......................................22

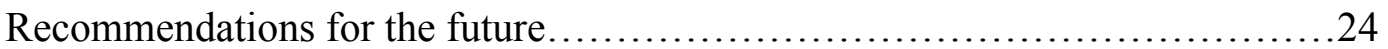

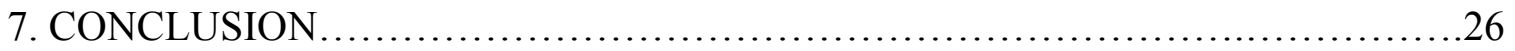

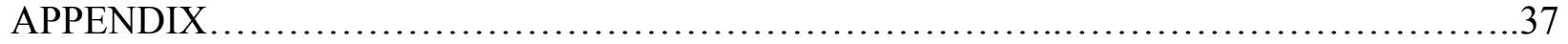

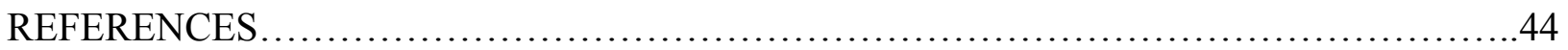




\section{LIST OF TABLE}

1. Other topics of sleep medicine included in the curriculum...........................27 


\section{LIST OF FIGURES}

1. Map of responding programs versus non-responding programs ..........................28

2. Number of responding schools per region........................................29

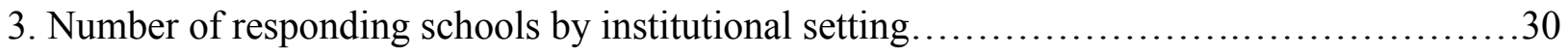

4. Topics that in the dental hygiene curriculum........................................ 31

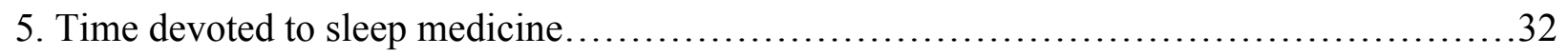

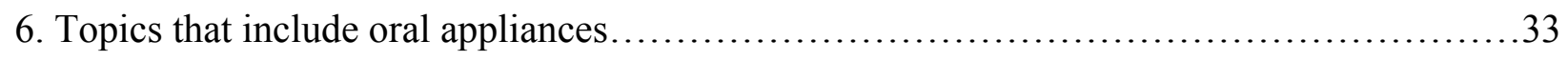

7. Topics dental hygiene students inquire/discuss with their patients.......................34

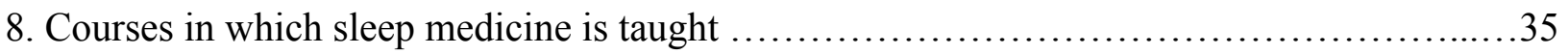

9. Dental hygiene faculty opinion on sleep medicine in dental hygiene education................36 


\section{LIST OF ABBREVIATIONS}

ADHA American Dental Hygienists’ Association

DH Dental Hygiene

MAD Mandibular Advancement Device

OA Oral Appliances

OAT Oral Appliance Therapy

OSA Obstructive Sleep Apnea

SM Sleep Medicine

SB Sleep Bruxism

UNC-CH The University of North Carolina- Chapel Hill 


\section{INTRODUCTION}

The National Sleep Foundation reported that 70 million Americans chronically suffer from approximately 60 medically recognized sleep disorders, estimated to create an annual economic burden of hundreds of billions of dollars. ${ }^{1}$ Sleep disorders may be life threatening and are associated with many other health problems such as hypertension, ${ }^{2,3}$ congestive heart failure, ${ }^{4}$ type II diabetes, ${ }^{5}$ periodontitis, ${ }^{6}$ coronary heart disease, ${ }^{7}$ depression, ${ }^{8}$ and a shorter life span. ${ }^{9}$ Although a significant health impact and increasing economic burden, many of these conditions remain undiagnosed and untreated. ${ }^{10,11}$ Prevention and early detection are critical since these potentially life threatening disorders are treatable.

In order to effectively address this issue, healthcare professionals must collaboratively work together in the identification, education, and treatment of patients with sleep disorders. However, clinicians do not receive adequate predoctoral education about the etiology, identification or treatment of sleep disorders. Studies report that little time is allocated to sleep

medicine in medical, ${ }^{12-14}$ and dental school curricula. ${ }^{15-17}$ To date there are no reported papers on the sleep medicine content in dental hygiene education. To address this question, we conducted a study to assess the amount of sleep medicine content dental hygiene students receive during their education. 


\section{REVIEW OF THE LITERATURE}

Sleep medicine is a recently recognized branch of clinical medicine devoted to the diagnosis and treatment of individuals suffering from chronic sleep loss or sleep disorders. ${ }^{18}$ Comprising of approximately 60 disorders, sleep medicine includes conditions classified into categories including sleep-related movement disorders, sleep related breathing disorders and insomnias.

Dental sleep medicine treatment is becoming more common within the dental profession. Dental sleep medicine focuses on the management of sleep bruxism and sleep-related breathing disorders (SRBD), which includes snoring, obstructive sleep apnea (OSA), with oral appliance therapy (OAT) and upper airway surgery. ${ }^{19}$

\subsection{Sleep- related Movement Disorders}

Sleep bruxism (SB), classified by the American Academy of Sleep Medicine as a sleeprelated movement disorder can cause occlusal wear, muscle pain, temporomandibular disorder (TMD), and is associated with headaches. ${ }^{20}$ Sleep bruxism affects 8 percent of Americans but the prevalence of SB is estimated to be much higher in patients with sleep-disordered breathing. ${ }^{20}$ This disorder has comorbid medical conditions such as insomnia, attention deficit disorder (ADHD), depression and gastro-esophageal reflux. ${ }^{20}$ Although no therapy can completely cure SB, oral appliances that prevent the upper and lower teeth from contacting are used to effectively manage symptoms. ${ }^{20}$

Periodic limb movement disorder (PLMD) is another sleep-related movement disorder characterized by limb movements during sleep. More often these repetitive motions occur in the 
toes, ankles, knees and hips every 20-40 seconds. Poor sleep and daytime sleepiness are the most common symptoms. $^{21}$

\subsection{Sleep-related Breathing Disorders (SRBD)}

There are several types of sleep-related breathing disorders. Primary snoring is the most common obstructive SRBD. This condition represents the first stage of increased upper airway resistance but can also remain a benign nuisance, usually noted by the patient's family member or bed partner. ${ }^{22}$ However, snoring is not a condition to be ignored as it may be symptomatic of possible comorbidities such as sleep apnea ${ }^{1}$ or hypertension. ${ }^{23}$ Snoring can usually be treated with an oral appliance that moves the jaw or tongue forward. ${ }^{22}$

Central sleep apnea is a non-obstructive SRBD caused by an imbalance in the brain and central nervous system. The brain ceases to send the proper signals to initiate breathing and the person experiences "apnea" or loss of breath during sleep. ${ }^{24}$ This disorder causes nighttime sleep awakening, daytime sleepiness and increases risk for cardiovascular disease. ${ }^{25}$ Central sleep apnea is more difficult to treat than obstructive sleep apnea and it is not thought to respond to oral appliances. $^{24}$

Obstructive sleep apnea (OSA) is more common than central sleep apnea and requires long-term management. OSA usually occurs when fat buildup or loss of muscle tone allow the windpipe to collapse during breathing. Thus, both anatomical and neuromuscular factors contribute to the etiology of OSA. The blocked airflow disrupts the person's sleep, awakening them enough to breathe. The sufferer proceeds to fall back into deeper sleep, repeating the cycle up to hundreds of times a night. The most common symptom of OSA is excessive daytime sleepiness. ${ }^{24}$ Approximately 1 in 5 American adults experience mild OSA and 1 in 15 have 
moderate or severe sleep apnea. Many are unaware of their disorder. ${ }^{26}$ If left untreated, OSA may be life threatening and has been associated with many other health problems. ${ }^{2-7}$

\subsection{Other Sleep Disorders}

Insomnia relates to an insufficient amount of sleep. The American Academy of Sleep Medicine recognizes that a person with insomnia may have a hard time initiating sleep, struggle maintaining sleep, and experience non-restorative sleep. ${ }^{27}$ Insomnia affects approximately 1 in 3 adults $^{28}$ and is accompanied by reduced social and occupational functions, restlessness, irritability, anxiety, daytime fatigue and tiredness. ${ }^{21}$ Shift work, longer working hours, technology, economic stress, and the fast pace lifestyles of today's society have detrimental effects on the nation's sleep quality.

\subsection{Sleep Medicine and Overall Health}

As noted earlier, sleep disorders are associated with a wide range of health issues, one being congestive heart failure. A 2014 study by Chen et. al., found that patients with moderate to severe OSA tend to have cardiac dysfunction. ${ }^{4}$

Sleep disorders are also associated with chronic conditions such as type II diabetes. A cross-sectional study by Knutson et al. revealed that sleep duration and quality were significant predictors of glycemic control. The results of the study suggest that optimizing sleep duration and quality can improve glucose control in patients diagnosed with type II diabetes. ${ }^{5}$

OSA has also been suggested to be a risk factor for periodontitis. A cross-sectional study found a 77-79 percent prevalence of periodontitis within a group of 66 patients diagnosed with OSA. ${ }^{29}$ The study found significant correlations between periodontal clinical attachment and total sleep time. A more recent study found a significant association between moderate or severe 
periodontitis and risk for OSA. ${ }^{6}$ Sixty six percent of periodontitis cases screened high risk of OSA compared with 28 percent of controls.

\subsection{Treatments for Sleep Disorders}

The "gold standard" for treating OSA is continuous positive airway pressure (CPAP) therapy. The CPAP machine utilizes positive airflow via mask on the mouth and/or nose to keep the airway open during sleep. CPAP therapy improves sleep quality and is effective for many people. ${ }^{30}$ However, some patients find this treatment uncomfortable and intolerable. Side effects include nasal congestions, drippy nose, nasal irritation, skin lesions, eye irritation, and dry mouth. $^{30}$

There are other options for those patients who are not compliant with CPAP therapy. The American Academy of Sleep Medicine now recognizes the use of oral mandibular advancement devices (MAD), a type of oral appliance, to treat snoring or mild to moderate obstructive sleep apnea. $^{22}$ These oral appliances are unobtrusive, quiet, and do not require a power source. However, side effects include jaw pain, muscle stiffness, dry mouth, hyper-salivation and bite change. ${ }^{22}$ Contraindications to OAT include periodontal disease, TMD, and number of remaining teeth. Common intra-oral findings of sleep disorders are large tongue with scalloped borders, tooth wear, acid erosion. ${ }^{31}$

Most recent studies show that compared to CPAP therapy, oral appliance (OA) therapy is equally as effective for patients with mild to moderate OSA. Some studies show that over 60 percent of patients with severe OSA can be adequately treated, a percentage much higher than originally thought. ${ }^{32-34} \mathrm{OAT}$ is a valid and less invasive alternative form of treatment for patients who cannot comply with CPAP therapy and for patients with mild or moderate disease and 
prefer them as an option for treatment. ${ }^{22} \mathrm{~A}$ recent randomized controlled clinical trial showed that oral appliances reduce blood pressure for patients with OSA and hypertension. ${ }^{35}$

The tongue-retaining device is another type oral appliance used for sleep-related breathing disorders. The device widens the upper airway during sleep, holding the tongue forward. These devices are only recommended when other treatments are not possible or have failed. ${ }^{36}$

Occlusal guards are used to manage sleep bruxism but are not effective in treating sleeprelated breathing disorders. Some studies have shown that occlusal guards can even make sleepdisordered breathing worse. ${ }^{37}$

\subsection{Professional Education about Sleep Disorders}

Currently, healthcare professionals do not receive adequate education about the pathology, etiology, or treatment of sleep disorders. An Institute of Medicine (IOM) Committee on Sleep Medicine and Research concluded that awareness among the public and healthcare professionals is low. ${ }^{1}$ There are too few professionals dedicated to sleep problems and there are too few educational programs that include sleep medicine to meet the current demands.

A Taskforce 2000 survey indicated that medical students receive limited education in sleep medicine. The results showed that predoctoral students receive an average of 2.1 hours in sleep medicine while postgraduate students received an average of 4.8 hours. ${ }^{14}$ This study illustrates a slight increase from a 1993 survey revealing an average of less than two hours of sleep medicine included in the medical school curriculum. ${ }^{38}$ Although medical schools dedicate little time in their curriculum to sleep medicine, integrating sleep topics into the medical school curriculum and competency-based goals and teaching strategies have been proposed. ${ }^{14}$ 
While little is being taught to medical students, some healthcare professions educators believe that entire programs should be developed for sleep medicine. A recent study revealed support for a bachelor's degree in sleep science and technology. ${ }^{39}$ Using questionnaires, directors from accredited polysomnography, electroneurodiagnostic technology, and respiratory care educational programs were assessed. Seventy-four percent of the directors agreed that demand for qualified sleep technologists will increase, and seventy-nine percent of respondents believed that sleep centers need technologists with advanced level training or specialization. ${ }^{39}$

Sleep medicine is gradually being incorporated into some of the pre-doctoral dental school curriculum although formal accreditation standards have yet to be established. A survey in 2003 was conducted to determine which of the 64 North American dental schools include sleep medicine or upper airway sleep disorders (UASD) in their curriculum. Out of the 43 responding schools, 42 percent were found to be teaching treatment of sleep disorders with oral devices. The average number of didactic hours devoted to instruction in these subjects was 2.5 , but the level and degree were not reported. ${ }^{17}$

Another recent survey of US dental schools reported and average of 3.92 hours (sd=3.39) among schools with curriculum time in sleep medicine and 2.96 hours averaged across all responding schools, including those who did not include sleep medicine in their curriculum. ${ }^{15}$ The main topics included were sleep related breathing disorders and sleep bruxism. The survey was sent to the 58 US dental schools achieving an 87.5 percent response rate.

Another study in published in 2004 evaluated the knowledge, opinions, and clinical experience of general practice dentists toward OSA and OAT. The survey revealed that 58 percent of dentists did not know possible common signs and symptoms of OSA. The survey also showed that 55 percent could not identify the mechanism of mandibular advancement devices 
and 46 percent were not aware that an oral appliance could be used to treat mild sleep apnea. However, almost every respondent agreed that OSA is a life-threatening disease that needs to be addressed by more professionals, including dentists. ${ }^{40}$

Results of a quality assurance inspection at the University of Tennessee Health Science Center College of Dentistry showed that only ninety-two patients in the database admitted to "snoring" and "sleep apnea". Since these conditions were not listed in the medical history questionnaire, the authors concluded that the statistics did not represent the national epidemic, which further implied a need for increasing student awareness. ${ }^{16}$

In response, a pioneering program at the University of Tennessee Health Science Center College of Dentistry was implemented to incorporate sleep medicine in the predoctoral program. Fourth year dental students take a course titled "Advanced TMD and Sleep Disordered Breathing." The conditions 'sleep apnea' and 'snoring' have also been added to the medical history questionnaire. The program proposes a rotation for fourth year dental students to shadow sleep clinicians. ${ }^{16}$

Countries outside of the US are addressing the lack of sleep medicine education in dental schools. At the University of British Columbia (UBC) in Vancouver, Canada the Division of Orthodontics teaches a course on sleep-disordered breathing. The students are provided with a background in sleep medicine, OAT and medical co-operation. ${ }^{41}$

According to the American Dental Hygienists' Association (ADHA), 334 entry-level accredited dental hygiene programs currently exist in the United States. Out of these programs, 287 offer an associates degree, 53 offer a bachelor's degree, and 8 offer a certificate. Some schools offer multiple degree and/or certificate options. Accredited dental hygiene programs require an average of 2,910 clocks hours of training. ${ }^{42}$ 
In 2010, there were 7,000 dental hygiene graduates and 4,996 DDS graduates. The number of dental hygiene graduates has had a 73.4\% increase from 1986-2010 and dental graduates had a $0 \%$ percent increase. ${ }^{43}$ 


\section{INTRODUCTION AND LITERATURE REVIEW}

Sleep medicine is a recently recognized branch of clinical medicine devoted to the diagnosis and treatment of individuals suffering from chronic sleep disorders. ${ }^{18}$ The National Sleep Foundation reported that 70 million Americans chronically suffer from approximately 60 medically recognized sleep disorders, estimated to create an annual economic burden of hundreds of billions of dollars. ${ }^{1}$

Of the 60 recognized sleep disorders, sleep bruxism (SB), snoring and obstructive sleep apnea (OSA) are treated by dentists. Sleep bruxism (SB) is characterized by clenching or grinding of the teeth during sleep, potentially causing occlusal wear, muscle pain and temporomandibular disorder (TMD). ${ }^{20}$ Although no therapy can completely cure SB, oral appliances that prevent the upper and lower teeth from contacting are used to effectively manage symptoms. $^{20}$

Primary snoring represents the first stage of increased upper airway resistance but can also remain a benign nuisance, usually noted by the patient's family member or bed partner. ${ }^{22}$ Snoring can usually be treated with an oral appliance that moves the jaw or tongue forward. ${ }^{22}$

Another disorder managed by dentists, OSA, is the collapse of the upper airways during sleep, resulting in airflow obstruction. The sufferer proceeds to fall back into deeper sleep, repeating the cycle up to hundreds of times a night. ${ }^{24}$ Approximately 1 in 5 American adults experience mild OSA and 1 in 15 have moderate or severe sleep apnea. ${ }^{26}$ OAT has been shown to be equally as effective as the gold standard treatment, continuous positive airway pressure (CPAP). ${ }^{22,32,33}$ Contraindications to OAT include periodontal disease, TMD, and number of 
remaining teeth. Common intra-oral findings of sleep disorders are large tongue with scalloped borders, tooth wear, acid erosion. ${ }^{31}$

Sleep disorders may be life threatening and are associated with many other health problems such as hypertension, ${ }^{2,3}$ congestive heart failure, ${ }^{4}$ type II diabetes, ${ }^{5}$ periodontitis, ${ }^{6}$ coronary heart disease, ${ }^{7}$ depression, ${ }^{8}$ and a shorter life span. ${ }^{9}$ Although a significant health impact and increasing economical burden, many of these conditions remain undiagnosed and untreated. ${ }^{10,11}$ Prevention and early detection are critical since these potentially life threatening disorders are treatable.

In order to effectively address this issue, healthcare professionals must collaboratively work together in the identification, education, and treatment of patients with sleep disorders. However, clinicians do not receive adequate predoctoral education about the etiology, identification or treatment of sleep disorders. Studies report that little time is allocated to sleep medicine in medical, ${ }^{12-14}$ and dental school curricula. ${ }^{15-17}$ To date there are no reported papers on the sleep medicine content in dental hygiene education. To address this question, we conducted a study to assess the amount of sleep medicine content dental hygiene students receive during their education. 


\section{METHODS AND MATERIALS}

An 18-question survey was developed in fall 2012 to assess the amount of sleep medicine content included in dental hygiene education. The survey was adapted from the questionnaire created and used by Simmons and Pullinger ${ }^{15}$ to evaluate dental sleep medicine in the predoctoral dental curriculum. The survey instrument (Appendix) was formatted into five sections with questions addressing the following topics: 1) sleep medicine in the didactic curriculum (5 questions) 2) sleep medicine in the laboratory/clinical instruction (3 questions) 3) other sleep medicine topics (3 questions) 4) respondents' opinions about sleep medicine (3 questions) and 5) program demographics (4 questions). Some questions asked the respondent to select the best answer while others asked to "choose all that apply", "none of the above" or "other" and gave a space to specify. Respondents were asked to answer the questions according to the 2012-13 curriculum in their program.

Prior to administering the survey nationwide, a pilot survey was emailed to seven dental hygiene faculty members from North Carolina, Oregon, the District of Columbia, Iowa and Maine to test for format, content, readability and time taken for completion. Faculty members were asked to provide feedback and suggestions. Upon review of the pilot study data, the questionnaire was revised for clarity and content. Notably, the faculty members were unfamiliar with the term "sleep medicine" used throughout the survey, causing some inaccurate answers. To provide clarification of what sleep medicine encompasses, a reiteration of "includes sleep bruxism, snoring and OSA" was provided in parenthesis after each appearance of the phrase "sleep medicine." 
A cover letter and survey was emailed to 334 dental hygiene program directors in the US. The survey instrument was answered via Qualtrics. Email addresses were obtained through the ADHA website.

The first mailing occurred in April 2013. Non-respondents were emailed a second time in May 2013 and a third time in June 2013. To increase the response rate, individual follow-up phone calls were made to the remaining schools using phone numbers obtained through the ADHA.

Results were tabulated from the output downloaded through Qualtrics. The survey responses were reported as descriptive statistics with mean and standard deviation. Response frequencies, means and standard deviations were based on the number of programs responding to the individuals' questions. To assess bias, a Fisher's exact test was utilized to determine if the percentages of responding programs, and the responses to the questions differed by geographic region or institutional setting. To determine if the sample was representative of the population by institutional setting and region a chi-square test was performed. 


\section{RESULTS}

\section{Demographics of respondents}

A total of 118 out of 334 programs participated in the electronic survey for a response rate of 35.3 percent. Not all respondents answered every question, but a minimum of 110 programs responded to most questions. The geographic distributions of responding and nonresponding programs are depicted by Figure 1. Most programs, both total number of schools and those responding to the survey, were in the South (Figure 2). The least number of programs was in the Northeast. The percentage of programs responding to the survey from the different geographic regions did not differ significantly from the percentage of all programs in the different geographic regions $(\mathrm{p}=0.92)$. This indicates that the programs in no geographic region were more likely to respond to the survey than another region.

Most of the respondents were from non-university based programs, followed by college or universities without a dental schools and then colleges or universities with a dental school (Figure 3). The percentage of programs responding to the survey from different institutional settings differed significantly from the percentage of all programs from the different institutional settings $(p=0.0001)$. Specifically, a relatively higher proportion of programs at colleges or universities with a dental school and a relatively lower proportion of non-university based programs responded to the survey. 


\section{Didactic curriculum}

The mean number of total hours devoted to sleep medicine was $1.55(\mathrm{sd}=1.37, \mathrm{n}=114)$.

Of those schools reporting a total time of 1 or more hours $(n=92)$ the mean number of total hours was $1.92(\mathrm{sd}=1.27)$.

Sleep bruxism

Over two thirds, $69 \%$ of programs, reported that sleep bruxism was taught in their dental hygiene curriculum (Figure 4). The mean time devoted to sleep bruxism in the didactic curriculum was 1.03 hours $(\mathrm{sd}=0.95)$. The mean time did not differ by geographic region $(p=0.06)$ or by institutional setting $(p=0.84)$.

When asked to estimate the number of hours dedicated to sleep bruxism, the majority of schools indicated one hour of their didactic curriculum $(57 \%, n=64)$, while $26 \%(n=29)$ of the responding programs reported that no time (0 hours) was devoted to sleep bruxism (Figure 5). The remaining $18 \%(n=20)$ of responding schools indicated 2 or more lecture hours on sleep bruxism. Of those programs reporting 1 or more hours on sleep bruxism in the didactic curriculum $(74 \%, \mathrm{n}=84)$, the mean time was 1.38 hours $(\mathrm{sd}=0.85)$.

All other topics in sleep medicine

Obstructive sleep apnea was taught most frequently, in $32 \%(n=36)$ of programs (Figure 4). Snoring was included in $25 \%(n=28)$ of the responding programs. Nine percent of programs $(n=10)$ included other topics such as insomnia and upper airway respiratory syndrome (UARS).

The mean time devoted to all other topics in sleep medicine in the didactic curriculum, excluding sleep bruxism, was 0.54 hours $(\mathrm{sd}=0.81)$. The mean time did not differ by geographic region $(p=0.23)$ but it did vary by institutional setting $(p=0.03)$. The mean time approximated 1 hour (0.95 hour) for programs at colleges and universities without a dental school, in contrast to 
programs at colleges and universities with dental schools ( 0.56 hour) and non-university based programs (0.41 hour).

When asked to estimate the number of hours dedicated to all other topics in sleep medicine, excluding sleep bruxism, the majority of schools indicated 0 hours of their didactic curriculum $(61 \%, n=69)$, while $28 \%(n=32)$ of the responding programs reported one hour (Figure 5). The remaining twelve schools (11\%) included 2 or more lecture hours on other topics. Of those programs reporting 1 or more hours to other topics, excluding sleep bruxism, in the didactic curriculum $(39 \%, \mathrm{n}=44)$, the mean time was 1.39 hours $(\mathrm{sd}=0.72)$. Sleep disordered breathing

Additional questions were asked to determine what was taught about sleep-disordered breathing in relation to its medical and dental implications and clinical assessment (See table). Fifty-seven percent $(n=61)$ of schools discuss the association between obstructive sleep apnea and periodontal disease, followed by oral and dental consequences of untreated sleep-related breathing disorders $(46 \%, n=49)$. Thirty-four percent $(n=36)$ of responding programs teach their students about the medical consequences of untreated sleep-disordered breathing but only $18 \%$ $(n=19)$ teach students the risk factors for OSA. Five percent $(n=5)$ teach the use of screening questionnaires to detect patients who are at increased risk of having sleep disordered breathing. Oral appliances

Questions regarding oral appliances revealed that $62 \%(n=70)$ of responding programs teach indications or contraindications for an oral appliance for sleep bruxism and only 35\% $(n=37)$ for snoring or OSA (Figure 6). Cleaning appliances for sleep bruxism is included in $66 \%$ of schools $(n=75)$ and in $32 \%$ of schools $(n=34)$, for snoring or OSA. Fifty-nine percent $(n=67)$ of responding schools include discussion of the types of appliances for sleep bruxism, and 35\% 
$(\mathrm{n}=37)$, for snoring or OSA. Only $17 \%$ did not discuss some aspect of oral appliances for sleep bruxism, while $52 \%$ did not discuss some aspect of oral appliances for snoring or obstructive sleep apnea.

\section{Clinical instruction}

Respondents were also asked to answer questions about students' clinical related training in sleep medicine (Figure 7). The majority of schools teach their students to inquire/discuss tooth attrition $(82 \%, \mathrm{n}=90)$ and sleep bruxism $(67 \%, \mathrm{n}=74)$. Snoring is discussed during student clinics in $22 \%(\mathrm{n}=24)$ of schools followed by obstructive sleep apnea, $(21 \%, \mathrm{n}=23)$. Each of excessive daytime sleepiness and insomnia was discussed in less than 15 percent of student clinics.

\section{Laboratory instruction}

The majority of responding schools $(74 \%, \mathrm{n}=81)$ did not spend time teaching students how to make oral appliances for sleep bruxism in the laboratory; while $26 \%$, $(n=29)$, of the programs dedicated one or more hours. With the exception of only three of these latter programs, the students made either one or two appliances.

\section{Course and faculty}

Figure 8 illustrates that sleep medicine is not included consistently in one specific course, rather it is covered in several courses. The courses most frequently identified were dental materials $(41 \%, \mathrm{n}=45)$ and periodontology $(37 \%, \mathrm{n}=41)$. It was not clear in which year sleep medicine was taught. Thirty percent $(n=33)$ of programs indicated the first year, while $24 \%$ $(\mathrm{n}=26)$ indicated the second year. Among responding programs, a dental hygiene faculty with a Master's Degree was most commonly responsible for teaching sleep medicine topics ( $49 \%$, 
$\mathrm{n}=54)$. In $37 \%(\mathrm{n}=41)$ of programs, a dentist teaches sleep medicine. A dental hygiene faculty with a bachelor's degree teaches sleep medicine in $18 \%(\mathrm{n}=20)$ of the responding schools.

\section{Opinions}

Seventy-one percent $(\mathrm{n}=77)$ of the respondents agree that sleep medicine content should be incorporated into the dental hygiene curriculum, and $93 \%(n=100)$ believe that sleep medicine is an important issue in healthcare (Figure 9). The majority of respondents agree that dental hygienists should have a role in identifying or assessing patients who have sleep bruxism $(85 \%$, $\mathrm{n}=92)$ and $\operatorname{OSA}(69 \%, \mathrm{n}=75)$. Eighty-five percent $(\mathrm{n}=93)$ of respondents said they were interested in learning more about sleep medicine. 


\section{DISCUSSION}

The goal of this survey was to assess the amount of sleep medicine in dental hygiene education and to determine if the institutional setting or geographic region had an effect on the education provided. Overall, it was found that U.S. dental hygiene programs include little, if any, education on sleep medicine. The mean number of total hours devoted to sleep medicine approximated only two hours among those programs that included sleep medicine.

Geographic region and institutional setting had no or little effect on how much sleep medicine is taught in dental hygiene programs. There was also no statistically significant difference in the amount of sleep bruxism taught or topics excluding sleep bruxism per institutional setting.

\section{SM in didactic, clinical and laboratory settings}

Sleep bruxism was the most commonly reported sleep medicine topic in dental hygiene programs. However, it was included mainly in the didactic setting, with little instruction in the clinical and laboratory setting. In only a few programs are dental hygienists taught to fabricate and deliver occlusal guards for sleep bruxism and less than half are taught how appliances affect

sleep bruxism. This is a similar finding to the Simmons and Pullinger ${ }^{15}$ study that reported 8.1\% of dental schools include a hands-on clinical laboratory experience.

Students in the majority of responding schools are taught to discuss sleep bruxism with their patients in clinic; however, the level of detail is unknown. Considering the little time devoted to sleep bruxism, one can conclude that dental hygiene students are limited in their 
ability and confidence to discuss the patient's disorder and the oral appliance used to treat the condition.

In comparison to sleep bruxism, the amount of education about other sleep medicine topics is minimal. Almost two-thirds of the schools do not include snoring or OSA at all. Sleep related breathing disorders such as OSA are being taught in twice the percentage of dental schools $(86.6 \%)$ than in dental hygiene programs. ${ }^{15}$ Most dental students graduate with some knowledge of OSA, while the majority of dental hygiene students graduate with very little knowledge at all.

Moreover, the results show that topics about oral appliances for OSA are seldom taught. Results from Simmons and Pullinger ${ }^{15}$ revealed that $86.5 \%$ of the dental schools teach students about OAT for sleep-disordered breathing, $75.7 \%$ discuss CPAP and $83.8 \%$ review diagnoses for OSA. In contrast, dental hygiene programs mainly discuss oral appliances in the context of sleep bruxism while little is discussed regarding OSA and OAT for OSA.

The results also show that topics in sleep medicine were not consistently taught in a particular year or specific course. It is possible that some schools teach sleep medicine in the first and second year and in multiple courses. When asked, "which course is sleep medicine taught", a relatively high number of respondents selected "other" demonstrating uncertainty in course identification. These findings suggest the need for a defined strategy for implementation of education in sleep medicine.

\section{Regional and institutional type representation}

The sample was representative of dental hygiene programs regionally but not by institutional setting. We observed a higher response rate from university settings, particularly from those programs with a dental school, than non-university settings. It is possible that 
because programs at a college or university were more likely to be involved in research, they were more willing to participate in the survey. It is also possible that programs without a university affiliation were more likely to exclude sleep medicine content in the curriculum and thus, there was less interest or motivation to participate in the survey.

\section{Limitations of the study}

A limitation of our study was a low response rate of 35 percent. Recent surveys to dental hygiene program directors have also received low response rates. For example, an online survey to DH programs, in 2008 reported a $56.9 \%$ response rate. ${ }^{44}$ Another study by Navickis et al. in 2009 received a $48 \%$ response rate from their online survey sent to US dental hygiene program directors. ${ }^{45}$ A third web-based survey sent to dental hygiene programs by DeBate et al. in 2007 only achieved a 46 percent response rate. ${ }^{46}$ The topics surveyed were patients with special needs, clinical assessment practices, and eating disorders respectively. The topic of sleep medicine is newer to dental hygiene faculty so it may account for the lower rate of response. In addition, upon calling the individual schools to increase our response rate for the current study, program directors frequently commented on the high volume of surveys sent to their email. The trend for a decreasing response rate might be attributed to the fact that dental hygiene program directors are receiving an increasing number of surveys. Although surveys are a valuable assessment tool their overuse in research may cause them to be overlooked.

It is also possible that the dental hygiene faculty members were unsure how to answer the questions since the topic is relatively new. A recent similar study by Simmons and Pullinger ${ }^{15}$ assessing dental schools received a much higher response rate of 87.5 percent. It is likely that dental schools are more familiar with sleep medicine education. The current survey was also 
longer, with 18 questions as compared to the Simmons and Pullinger ${ }^{15}$ survey, which had only 8 questions. The length and unfamiliar topic could have been a discouraging combination for many program directors. All considered, the lack of response is likely reflective of many factors, including lack of time by those requested to complete the survey and limited sleep education curriculum.

\section{Significance and findings}

The Commission on Dental Accreditation (CODA) for dental hygiene programs states that "dental hygiene science content must include health promotion and graduates must be competent in providing the dental hygiene process of care which includes comprehensive collection of patient data to identify the physical and oral health care status." ${ }^{43}$ This statement implies that the dental hygienist assesses the patient's overall health, which given the prevalence of and risks of untreated sleep-disordered breathing should include screening patients for sleep disorders.

The results of this survey reveal that dental hygiene faculty support sleep medicine in dental hygiene education. A majority of respondents agree that sleep medicine is an important issue in healthcare and are interested in learning more about it. We can conclude that with the support of dental hygiene faculty, the only obstacle is implementation.

\section{Relevance to dental hygienists}

The Institute of Medicine reports that a "new professional" is needed to emphasize crossdisciplinary responsibilities and accountability. ${ }^{1}$ Healthcare providers, including dental care professionals must work as a team to effectively address the rising sleep disease epidemic and treat patients according to their individual needs. 
Dental hygienists are on the frontline regarding prevention and counseling. They take pulse and blood pressure, review medications and medical histories, perform patient oral cancer screenings, tobacco cessation, nutritional counseling and extra-oral examinations. If sleep questionnaires were included in medical histories, the knowledgeable dental hygienist would also assess the patients' risk level and perform further inquiry or referral if needed.

Dental hygienists spend the majority of their time combating periodontitis with scaling, prophylaxis appointments, and oral hygiene instructions. Considering recent research that suggests OSA to be a predictor of periodontitis, ${ }^{6}$ dental hygienists should have knowledge about OSA in order to adequately treat and educate their patients for periodontal disease. The dental hygienist could have an effect on the patients' outcome of treatment since uncontrolled periodontitis is a contraindication to OAT.

The number of dental hygiene graduates has increased by 73.4 percent from 1986-2010 with seven thousand graduates in $2010 .{ }^{43}$ Sleep medicine incorporated into the dental hygiene curriculum could result in seven thousand more healthcare providers a year who are aware of sleep disorders. This could mean an increase in individual diagnosed with OSA and also better management and prognosis of those who are affected by the condition.

With the rising prevalence of sleep related breathing disorders and the use of oral appliances in their treatment, the dental hygienist should have proper education in sleep medicine. As these conditions often show oral implications detected in the dental office, dental providers should be knowledgeable of their etiology, clinical signs and symptoms, and treatment options. The DH curriculum should provide enough education of the diseases, so that the future 
dental hygienist can discuss the risk factors and symptoms with their patients and communicate effectively with other health professionals.

\section{Recommendations for the future}

Simmons and Pullinger ${ }^{15}$ suggested future recommendations for the dental school curricula that are equally valuable for dental hygiene program content. These recommendations include competencies to assess the students' ability to recognize and screen patients with comorbidities, discuss medical consequences of untreated sleep disorders, discuss available treatment options, and understand that snoring is more than a social issue and is related to serious conditions.

A main concern is where to include additional lectures and competencies into an already overcrowded dental hygiene curriculum. Also the question as to the number of lecture hours and clinical time needed to develop an appropriate understanding of the topics must be addressed. There are some options to consider, but these questions will need further exploration.

Certainly the didactic curriculum should include education on the common types of sleep disorders such as sleep bruxism, snoring and obstructive sleep apnea. The lecture(s) should include the definition and prevalence, clinical presentation, risk factors and consequences of untreated sleep disorders, and treatment options such as occlusal guards, CPAP and OAT for sleep-related breathing disorders. Clinical curriculum should include questions relating to sleep disorders in the medical history. Also, student clinical competencies could include recognizing patients with comorbidities, screening patients for OSA, recognizing common intra-oral findings and discussing sleep disorders with patients, and possibly recommending a visit to their physician. 
There are several options to include sleep medicine into the DH curriculum. One is to require certain topics be taught in existing courses of the first year, such as human anatomy or nutrition, a pre-requisite. This would make room to focus more on practical subjects relevant to dental hygiene and allow for more flexibility in general within the program. Another option would be to implement a short online course in sleep medicine, with posted lectures and online assessments. An online alcohol intervention course piloted to dental students significantly changed their knowledge, attitudes and behaviors ${ }^{47}$ proving this option to be a feasible consideration.

As sleep medicine is a multidisciplinary field, a third option would be to involve other professional education curriculums, encouraging inter and intra-professionalism. A sleep medicine course would involve dental hygiene students along with dental students, nursing students and/or medical students depending on what other programs are within the school. It is clear that all health professionals lack education in this area and a course together would create an awareness of the lack of sleep medicine in healthcare education and foster future professional relationships.

The dental hygiene profession is always growing and expanding with technology, social trends, epidemics, and research. The curriculum should reflect and adapt to provide proper education to successfully prepare future dental hygienists to become highly qualified healthcare providers. 


\section{CONCLUSION}

This study revealed that US dental hygiene curriculums include little education in sleep medicine with sleep bruxism being the main topic taught. Very little is being taught regarding OSA and oral appliances for sleep-related breathing disorders. If dental hygienists were more knowledgeable of sleep disorders, they could increase awareness and aid in the management of OAT. Further investigation should include how to implement sleep medicine in to the dental hygiene curriculum so that dental hygienists can take an active role in detecting and monitoring symptoms of sleep disorders. 


\section{TABLE AND FIGURES}

Table. Other topics in sleep medicine included in the curriculum

\begin{tabular}{|l|r|r|}
\hline Other topics of sleep medicine included in the curriculum & $\mathbf{n}$ & $\%$ \\
\hline Association between sleep bruxism and periodontal disease & 61 & $57 \%$ \\
\hline $\begin{array}{l}\text { Oral and dental consequences of untreated sleep-related breathing } \\
\text { disorders }\end{array}$ & 49 & $46 \%$ \\
\hline Medical consequences of untreated sleep-related breathing disorders & 36 & $34 \%$ \\
\hline Detecting risk factors for OSA & 19 & $18 \%$ \\
\hline Continuous Positive Airway Pressure (CPAP) therapy & 18 & $17 \%$ \\
\hline $\begin{array}{l}\text { Medical documentation required by a dental practice before treating a } \\
\text { patient with diagnosed or suspected OSA }\end{array}$ & 8 & $7 \%$ \\
\hline $\begin{array}{l}\text { Use of OSA screening questionnaires (STOP, STOP-BANG, } \\
\text { BERLIN, etc) }\end{array}$ & 5 & $5 \%$ \\
\hline Use of a pulse oximeter or other home sleep testing device & 5 & $5 \%$ \\
\hline Polysomnography and interpretation of sleep study reports & 3 & $3 \%$ \\
\hline
\end{tabular}


Figure 1. Map of responding programs versus non-responding programs

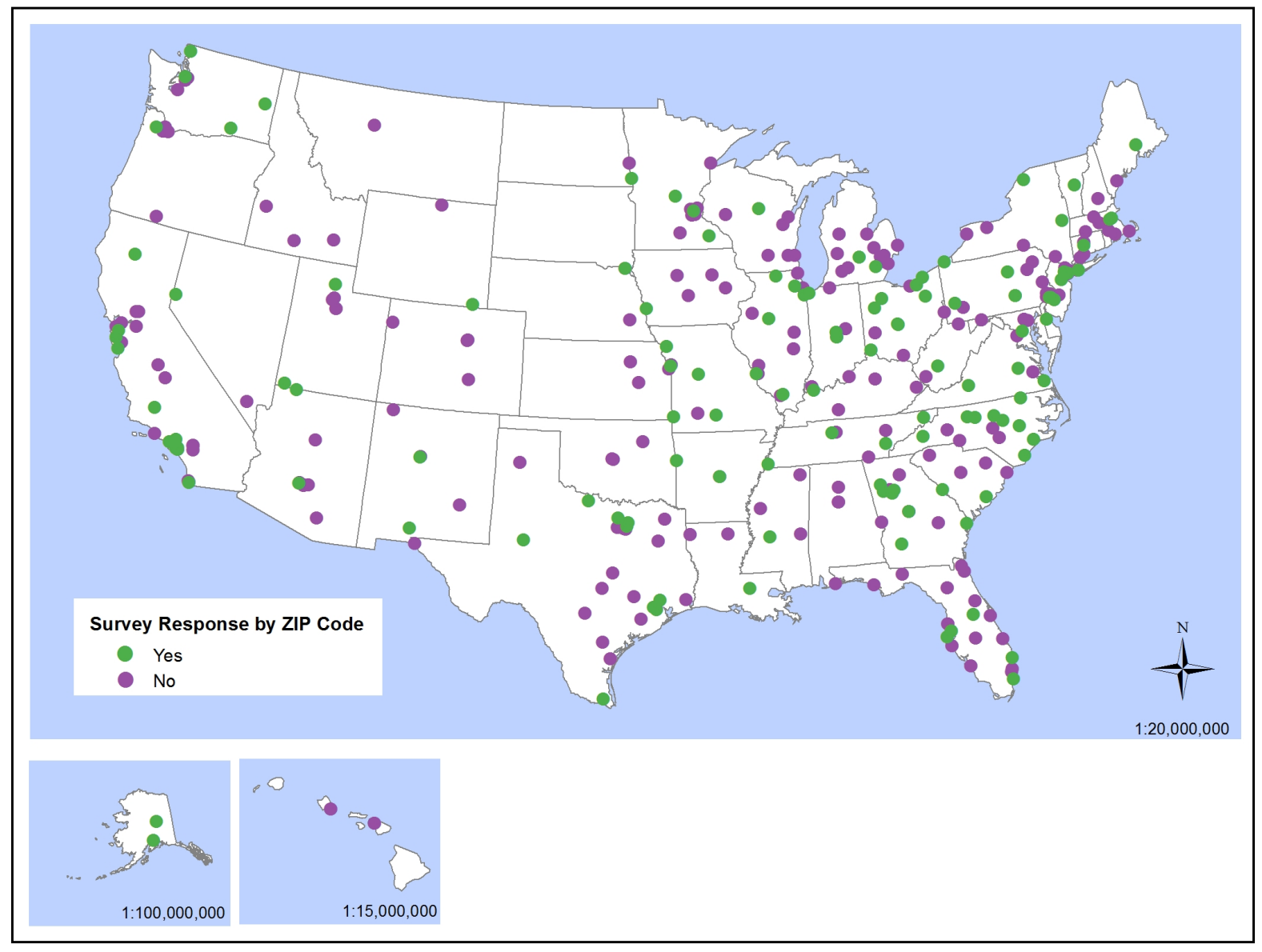


Figure 2. Number of responding schools per region. (Percentages compare the number of responding schools to the number of existing schools.)

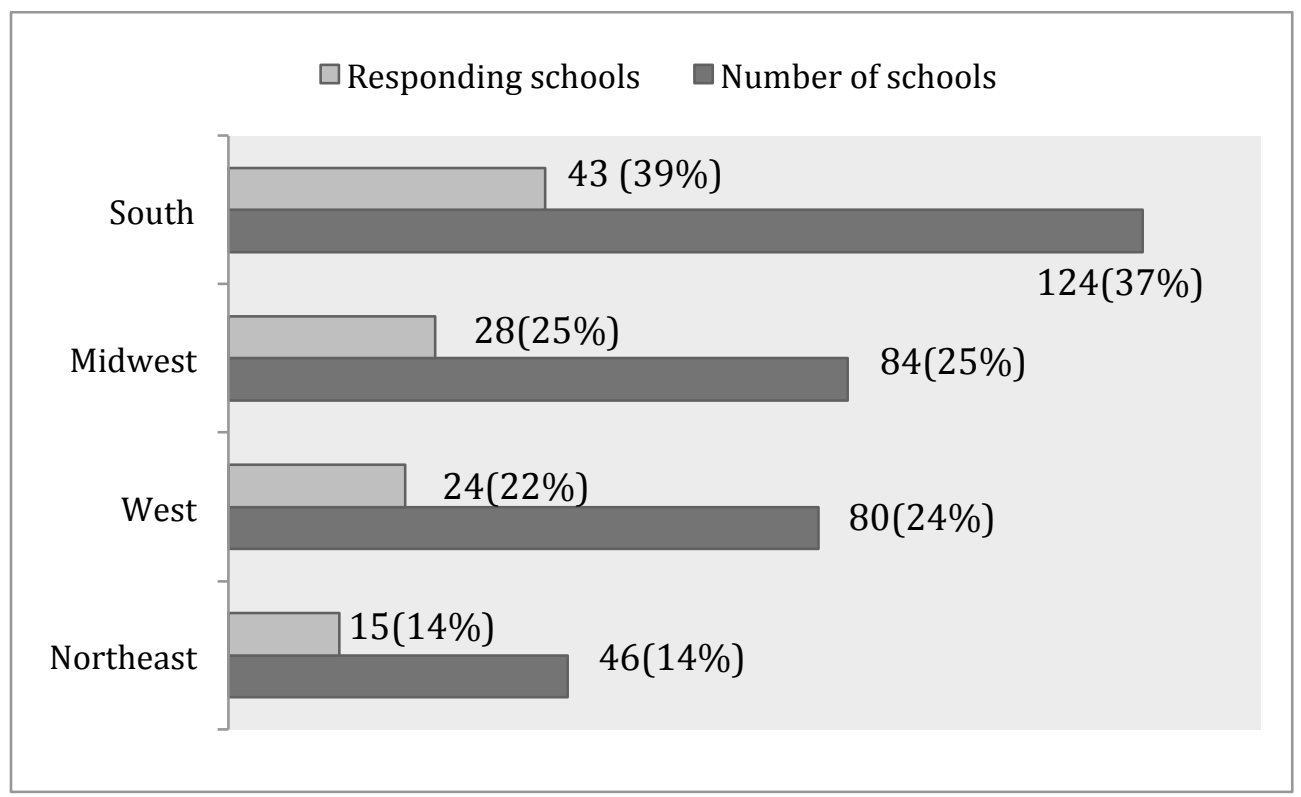


Figure 3. Number of responding schools by institutional setting. (Percentages compare the number of responding schools to the number of existing schools.)

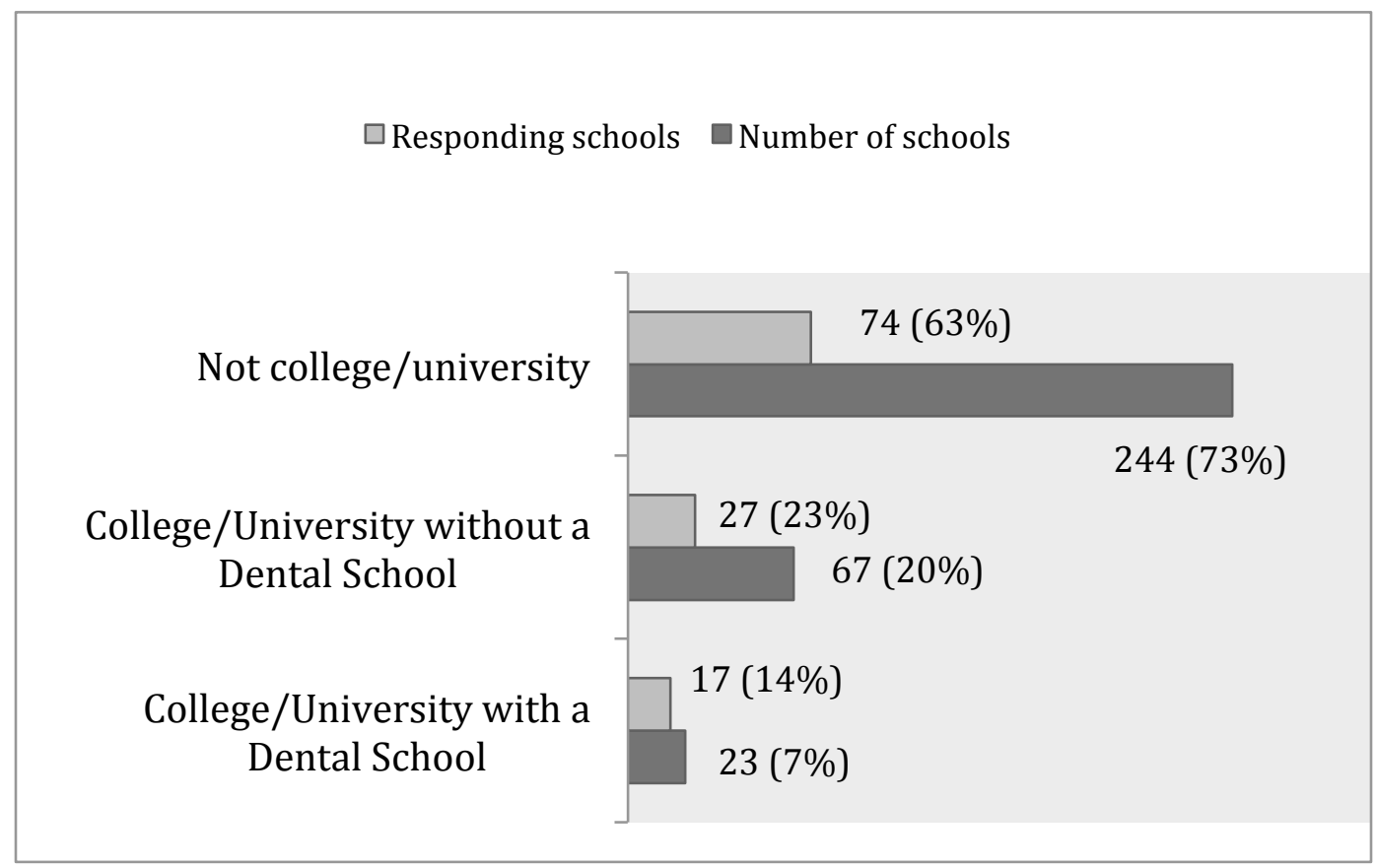


Figure 4. Topics taught in the dental hygiene curriculum

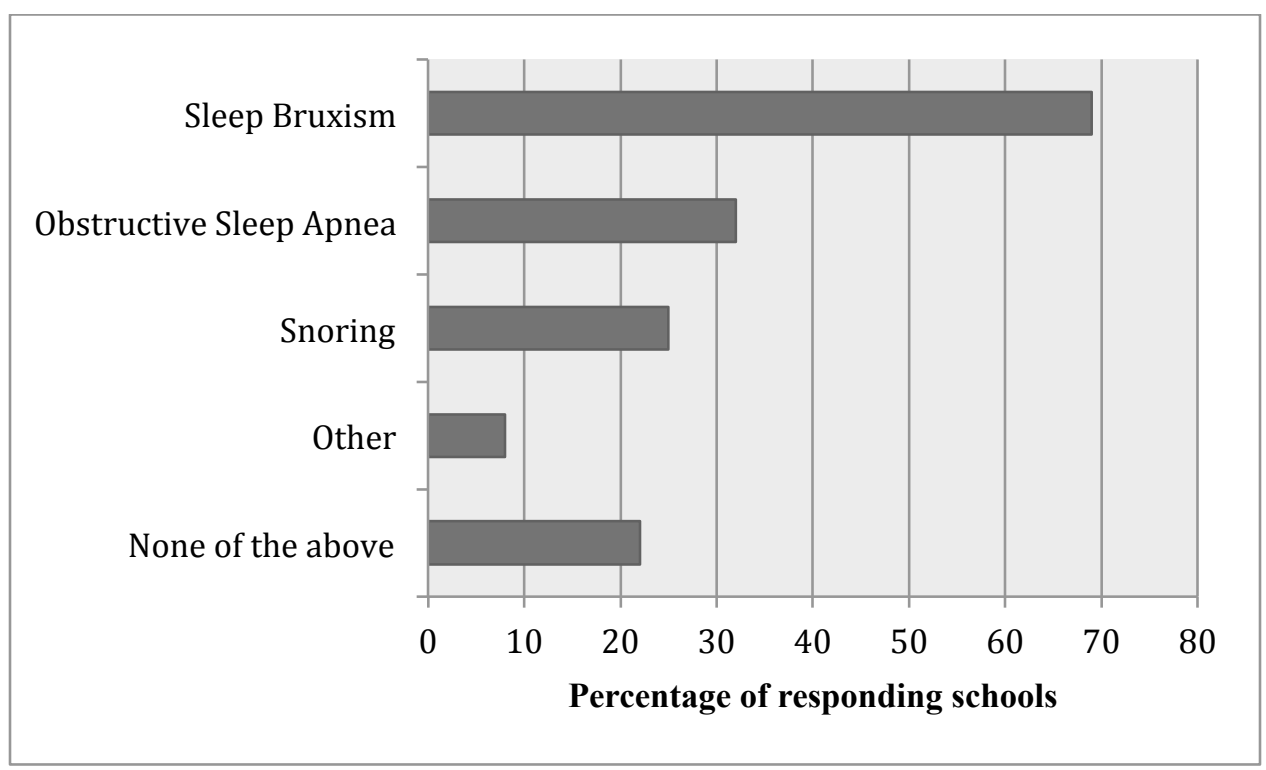


Figure 5. Time devoted to sleep medicine

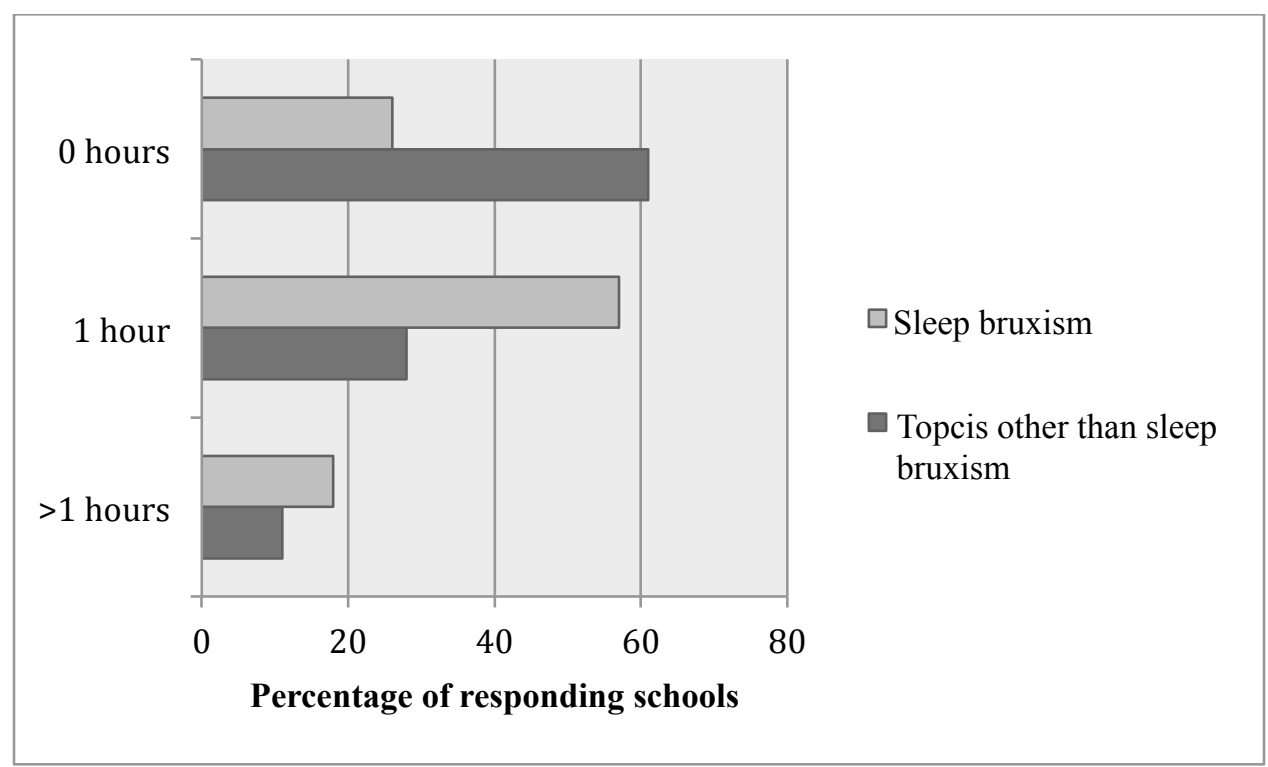


Figure 6. Topics that include oral appliances

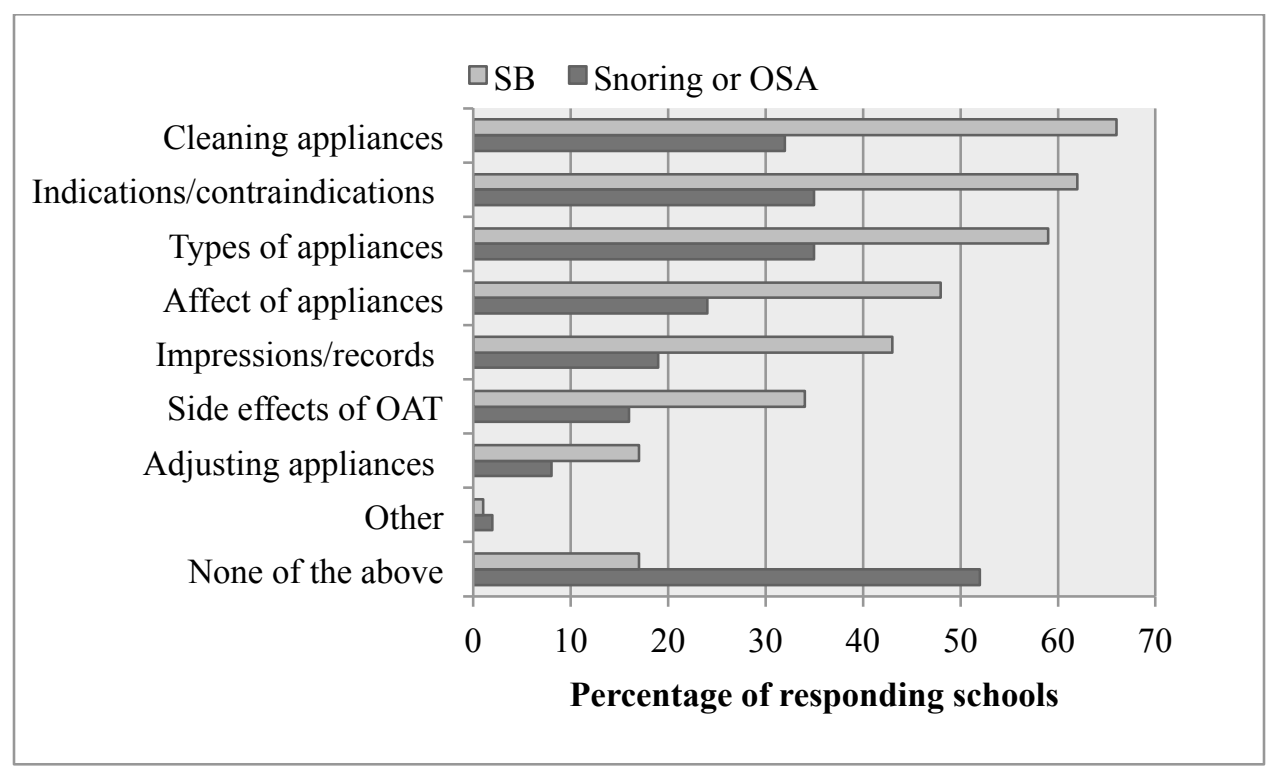


Figure 7. Topics dental hygiene students inquire/discuss with their patients

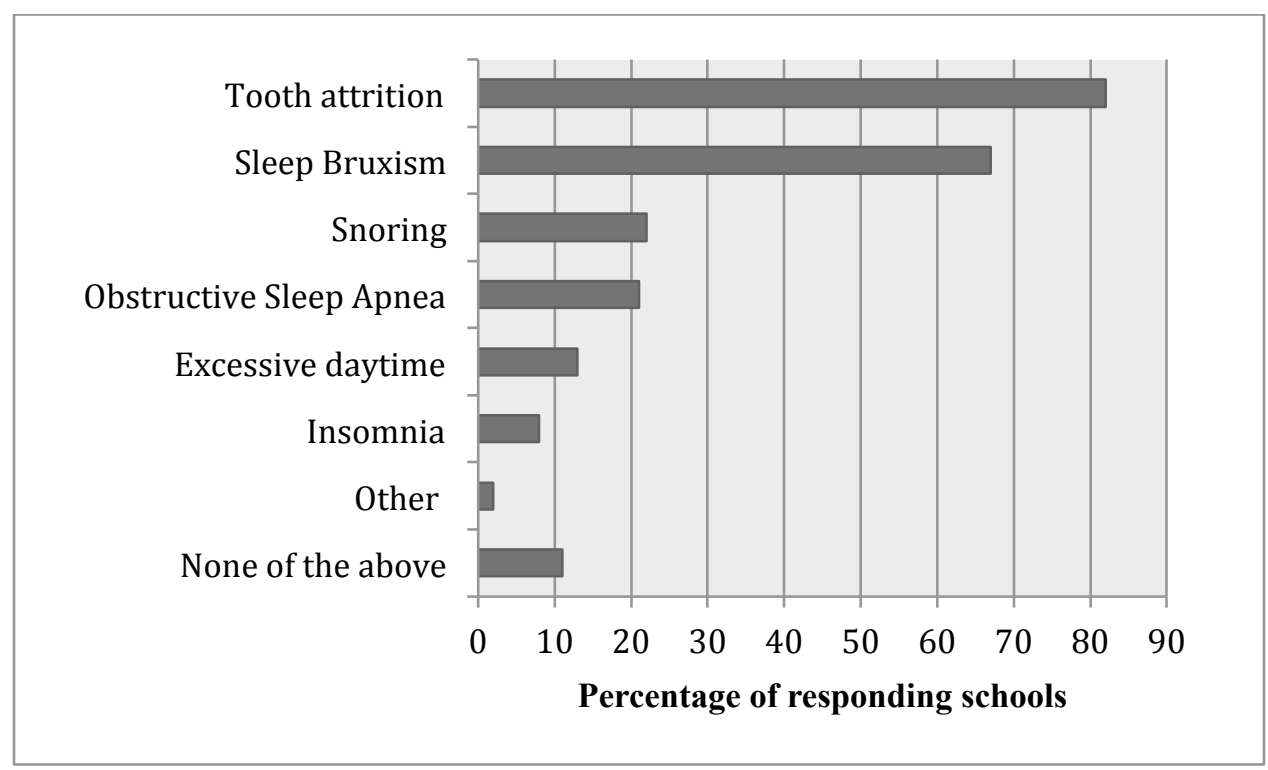


Figure 8. Courses in which sleep medicine is taught

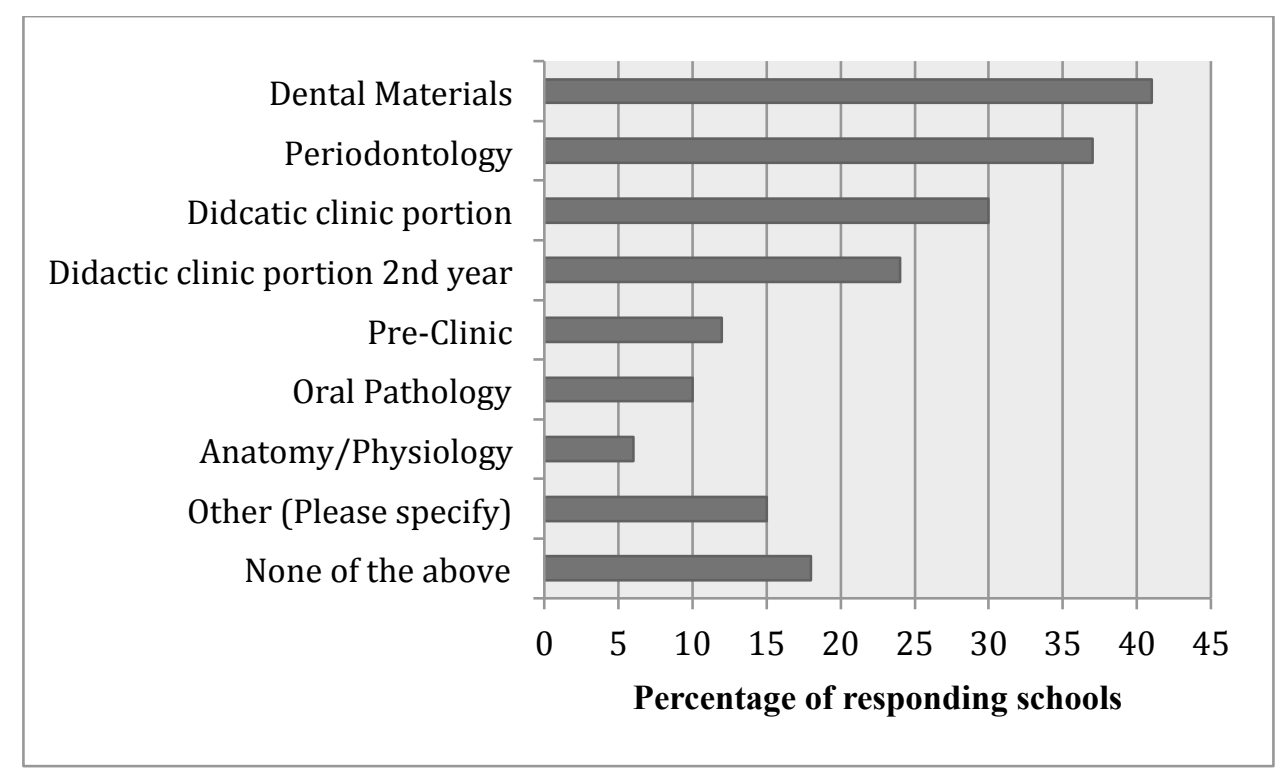


Figure 9. Dental hygiene faculty opinion on sleep medicine in dental hygiene curriculum

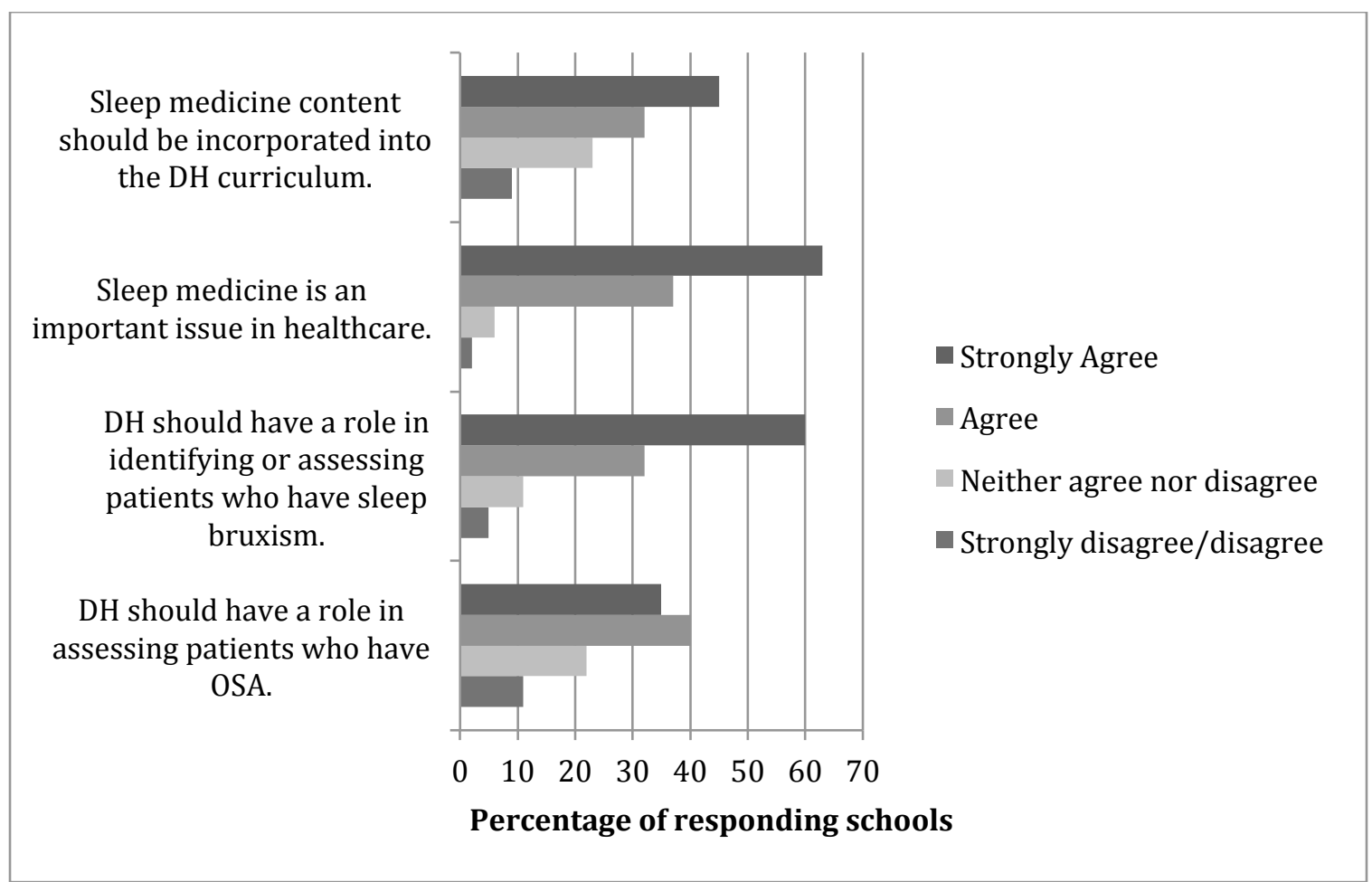




\section{APPENDIX}

Questionnaire- Sleep Medicine in Dental Hygiene Education

Dear Program Administrator,

Obstructive sleep apnea (OSA) is a disease that affects 1 in 5 American adults. This lifethreatening condition is currently widely undiagnosed. As more patients are affected, healthcare providers will need to be able to recognize, diagnose, and treat this condition.

Dental practices are beginning to help treat sleep bruxism, snoring and OSA with custom-made oral appliances, and dental hygienists are anticipated to play an increasingly important role in patient education, diagnosis, treatment, and patient management during this process.

This survey seeks to determine the amount of education dental hygiene students currently receive in schools around the United States on sleep medicine. We request that you, or the appropriate faculty at your institution, answer a brief questionnaire posted on Qualtrics.

We sincerely thank you in advance for your participation. The results of the completed study will be shared with you. 
For the 2012/2013 Academic year, please answer the following questions for your dental hygiene program.

Q1 Which of the following topics in Sleep Medicine are taught in your Dental Hygiene Curriculum for the 2012/2013 academic year? (Choose all that apply)

- Sleep Bruxism

Snoring

口 Obstructive Sleep Apnea

I Insomnia

Other sleep disorders not listed above (Please Specify)

None of the above

Q2 Number of total lecture hours spent on Sleep Bruxism in your didactic curriculum during the 2012/2013 academic year.
○ 0
O 1
○ 2
○ 3
○ 4
O 5 or more

Q3 Excluding lectures on Sleep Bruxism, what are the number of lecture hours spent on Sleep Medicine (includes snoring and Obstructive Sleep Apnea) in your 2012/2013 didactic curriculum?

$\begin{array}{ll}\text { O } & 0 \\ \text { O } & 1 \\ \text { O } & 2 \\ \text { O } & 3 \\ \text { O } & 4 \\ \text { O } & 5 \text { or more }\end{array}$

Q4 For 2012/2013 academic year, which topics regarding oral appliances for Sleep Bruxism are discussed? (Choose all that apply)

- Indications or contraindications for an appliance

- How appliances affect Sleep Bruxism

- Side effects of Oral Appliance Therapy

T. Types of appliances

Impressions or records needed for appliances

- Adjusting appliances to better the fit or occlusion

a Cleaning appliances

Other: Please specify

Done of the above 
Q5 Which topics regarding oral appliances for Snoring or Obstructive Sleep Apnea are discussed? (Choose all that apply)

$\square$ Indications and contraindications for an appliance

How appliances affect Snoring and OSA

- Side effects of Oral Appliance Therapy

Types of appliances

Impressions and records needed for appliances

Adjusting appliances to better the fit and occlusion

$\square$ Cleaning appliances

$\square$ Other (Please specify)

$\square$ None of the above

Q6 Which of the following topics are your students taught to inquire/discuss with their patients?

(Choose all that apply)

- Sleep Bruxism

$\square$ Tooth attrition

$\square$ Snoring

口 Obstructive Sleep Apnea

- Excessive daytime sleepiness

$\square$ Insomnia

$\square$ Other (Please specify)

ㄱone of the above

Q7 What is the average number of lab hours students spent learning how to make oral appliances for Sleep Bruxism in 2012/2013?

O 0

○ $1-2$

O $3-4$

O 5 or more

Q8 What is the average number of oral appliances for Sleep Bruxism made by each student in 2012/2013?

○ 0

O $1-2$

O 3-4

O 5 or more 
Q9 Other topics that are related to the clinical assessment/implications of Obstructive Sleep Apnea are listed below. Please choose all that are included in your curriculum.

Medical consequences of untreated sleep-related breathing disorders

O Oral and dental consequences of untreated sleep-related breathing disorders

- Association between sleep bruxism and periodontal disease

$\square$ Medical documentation required by a dental practice before treating a patient with diagnosed or suspected OSA

$\square$ Detecting risk factors for OSA

Use of OSA screening questionnaires (STOP, STOP-BANG, BERLIN, etc.)

$\square$ Use of a pulse oximeter or other home sleep testing device

P Polysomnography and interpretation of sleep study reports

$\square$ Continuous Positive Airway Pressure (CPAP) therapy

$\square$ Other (Please specify)

$\square$ None of the above

Q10 In which course(s) are topics in Sleep Medicine (includes sleep bruxism, snoring and Obstructive Sleep Medicine) taught? (Choose all that apply)

$\square$ Pre-Clinic

D Didactic clinic portion 1st year

$\square$ Didactic clinic portion 2nd year

$\square$ Dental Materials

Periodontology

$\square$ Oral Pathology

口 Anatomy/Physiology

Other (Please specify)

None of the above

Q11 During the 2012/2013 academic year, who is responsible for teaching Sleep Medicine (includes sleep bruxism, snoring and OSA) topics at your institution? (Choose all that apply)

Dental Hygiene faculty with a B.S. degree

Dental Hygiene faculty with an M.S. degree

$\square$ Dental Hygiene faculty with a $\mathrm{PhD}$

口 Dentist

Medical Doctor

Other (Please specify)

ㄱone of the above 
Q12 Please indicate your opinion for each of the following statements regarding Sleep Medicine (includes sleep bruxism, snoring and OSA) in dental hygiene.

\begin{tabular}{|c|c|c|c|c|c|}
\hline & Strongly Agree & $\begin{array}{l}\text { Somewhat } \\
\text { Agree }\end{array}$ & $\begin{array}{l}\text { Neither Agree } \\
\text { nor Disagree }\end{array}$ & $\begin{array}{c}\text { Somewhat } \\
\text { Disagree }\end{array}$ & $\begin{array}{l}\text { Strongly } \\
\text { Disagree }\end{array}$ \\
\hline $\begin{array}{c}\text { Dental } \\
\text { Hygienists } \\
\text { should have a } \\
\text { role in } \\
\text { identifying or } \\
\text { assessing } \\
\text { patients who } \\
\text { have Sleep } \\
\text { Bruxism. }\end{array}$ & $\mathrm{O}$ & 0 & 0 & O & O \\
\hline $\begin{array}{c}\text { Dental } \\
\text { Hygienists } \\
\text { should have a } \\
\text { role in } \\
\text { assessing } \\
\text { patients who } \\
\text { have } \\
\text { Obstructive } \\
\text { Sleep Apnea. }\end{array}$ & O & O & 0 & O & O \\
\hline $\begin{array}{c}\text { Sleep } \\
\text { Medicine } \\
\text { (includes sleep } \\
\text { bruxism, } \\
\text { snoring or } \\
\text { Obstructive } \\
\text { Sleep Apnea) } \\
\text { is an important } \\
\text { issue in } \\
\text { healthcare. }\end{array}$ & O & 0 & O & O & O \\
\hline $\begin{array}{c}\text { Sleep } \\
\text { Medicine } \\
\text { (includes sleep } \\
\text { bruxism, } \\
\text { snoring and } \\
\text { Obstructive } \\
\text { Sleep Apnea) } \\
\text { content should } \\
\text { be } \\
\text { incorporated } \\
\text { into the dental } \\
\text { hygiene } \\
\text { curriculum. }\end{array}$ & 0 & O & 0 & 0 & O \\
\hline
\end{tabular}


Q13 I am interested in learning more about Sleep Medicine (includes sleep bruxism, snoring and Obstructive Sleep Apnea)
$\mathrm{O}$ Yes
O No

Q14 Please rate the importance of incorporating each of the following topics into dental hygiene education

\begin{tabular}{|c|c|c|c|c|}
\hline & Very & Somewhat & Only a little & Not at all \\
\hline Snoring & 0 & 0 & 0 & 0 \\
Sleep Bruxism & 0 & 0 & 0 & 0 \\
$\begin{array}{c}\text { Obstructive Sleep } \\
\text { Apnea }\end{array}$ & 0 & 0 & 0 & 0 \\
$\begin{array}{c}\text { Oral Appliance } \\
\text { Therapy }\end{array}$ & 0 & 0 & 0 & 0 \\
$\begin{array}{c}\text { Risk factors for } \\
\text { sleep disordered } \\
\text { breathing }\end{array}$ & 0 & 0 & 0 & 0 \\
$\begin{array}{c}\text { Other (Please } \\
\text { specify) }\end{array}$ & 0 & 0 & 0 & \\
\hline
\end{tabular}

Q15 Please indicate the institutional setting of your dental hygiene program.

O Technical/Vocational Institute

Community/Junior College

O College/University with a Dental School

O College/University without a Dental School

Other (Please Specify)

Q16 Please indicate the region of your school.

O Northeast (Connecticut, Maine, Massachusetts, New Hampshire, Rhode Island, Vermont, New Jersey, New York, Pennsylvania)

O Midwest (North Dakota, South Dakota, Ohio, Wisconsin, Minnesota, Michigan, Indiana, Illinois, Kansas, Missouri, Nebraska, Iowa)

South (Delaware, District of Columbia, Florida, Georgia, Maryland, North Carolina, South Carolina, Virginia, West Virginia, Alabama, Kentucky, Mississippi, Tennessee, Arkansas, Louisiana, Oklahoma, Texas)

O West (California, Washington, Oregon, Colorado, Montana, Nevada, Utah, Wyoming, Idaho, Alaska, Hawaii, New Mexico, Arizona) 
Q17 Please indicate what type(s) of dental hygiene programs are offered at your school. (Choose all that apply)

$\square$ Certificate/Associate Degree

$\square$ Baccalaureate Degree

口 Masters Degree

$\square$ Other (Please Specify)

Q18 Please Indicate the number of students that will graduate in 2013.

O Less than 15

O $15-20$

O 21-25

O 26-30

O $31-35$

O $>36$

Q19 Comments 


\section{REFERENCES}

1. National Research Council. Sleep disorders and sleep deprivation: An unmet public health problem. Washington, DC: Institute of Medicine: National Academies Press; 2006.

2. Bosc LVG, Resta T, Walker B, Kanagy NL. Mechanisms of intermittent hypoxia induced hypertension. J Cell Mol Med. 2010;14(1-2):3-17.

3. Davies CW, Crosby JH, Mullins RL, Barbour C, Davies RJ, Stradling JR. Case-control study of 24 hour ambulatory blood pressure in patients with obstructive sleep apnea and normal matched control subjects. Thorax. 2000;55(9):736-740.

4. Chen YL, Su MC, Liu WH, Wang CC, Lin MC, Chen MC. Influence and predicting variables of obstructive sleep apnea on cardiac function and remodeling in patients without congestive heart failure. J Clin Sleep Med. 2014;10(1):57-64.

5. Knutson K. Role of sleep and duration and quality in the risk and severity of type 2 diabetes mellitus. Arch of Intern Med. 2006;166(16):1768-1774.

6. Ahmad N, Sanders A, Sheats R, Brame J, Essick G. Obstructive sleep apnea in association with periodontitis: A case-control study. J Dent Hyg. 2014;87(4):188-99.

7. Levy P, Pepin JL, Arnaud C, Baguet JP, Dematteis M, Mach F. Obstructive sleep apnea and atherosclerosis. Prog Cardiovasc Dis. 2009;51(5):400-410.

8. Zimmerman M, McGlinchey J, Young D, Chelminski I. Diagnosing major depressive disorder I: A psychometric evaluation of the DSM-IV symptom criteria. J Nerv Ment Dis. 2006;3(194):158-163.

9. Young T, Finn L. Epidemiological insights into the public health burden of sleep disordered breathing: Sex differences in survival among sleep clinic patients. Thorax. 1998;53(3):16-19.

10. Young T. Estimation of the clinically diagnosed proportion of sleep apnea syndrome in middle-aged men and women. Sleep. 1997;20(9):705-706.

11. Kapur V. Underdiagnosis of sleep apnea syndrome in U.S. communities. Sleep Breath. 2002;6(2):49-54.

12. Harding S, Berner E. Developing an action plan for integrating sleep topics into the medical school curriculum. Sleep Breath. 2002;6(4):155-160.

13. Federman D. Competency-based goals for sleep and chronobiology in undergraduate medical education. Sleep. 2003;26(3):251.

14. Rosen R, Mahowald M, Chesson A, et al. The taskforce 2000 survey on medical education in sleep and sleep disorders. Sleep. 1998;21(3):235-238. 
15. Simmons MS, Pullinger A. Education in sleep disorders in US dental schools DDS programs. Sleep Breath. 2012;16(2):383-392.

16. Ivanoff C, Hottel T, Pancratz F. Is there a place for teaching obstructive sleep apnea and snoring in the predoctoral dental curriculum? J Dent Ed. 2012;76(12):1639-1645.

17. Ivanhoe JR, Frazier KB, Parr GR, Haywood VB. The teaching and treatment of upper airway sleep disorders in North American dental schools. J Prosthet Dent. 2003;89(3):292-296.

18. Shepard JW,Jr, Buysse DJ, Chesson AL,Jr, et al. History of the development of sleep medicine in the United States. J Clin Sleep Med. 2005;1(1):61-82.

19. American Academcy of Dental Sleep Medicine. American Academy of Dental Sleep Medicine website. At: http://www.aadsm.org/whatisdentalsleepmedicine.aspx. Updated 2012. Accessed: 10/2013, 2013.

20. Carra M. Sleep bruxism: A comprehensive overview for the dental clinician interested in sleep medicine. Dent Clin N Am. 2012;56(2):387-413.

21. American Academy of Sleep Medicine. International classification of sleep disorders, 3rd ed. Darien, IL: J Clin Sleep Med, 2014.

22. Kushida CA, Morgenthaler TI, Littner MR, et al. Practice parameters for the treatment of snoring and obstructive sleep apnea with oral appliances: An update for 2005. Sleep. 2006;29(2):240-243.

23. Hu FB, Willett WC, Manson JE, et al. Snoring and risk of cardiovascular disease in women. J Am Coll Cardiol. 2000;35(2):308-313.

24. White DP. Pathogenesis of obstructive and central sleep apnea. Am J Respir Crit Care Med. 2005;172(11):1363-1370.

25. Burgess HJ, Kleiman J, Trinder J. Cardiac activity during sleep onset. Psychophysiology. 1999;36(3):298-306.

26. Young T, Peppard P, Gottlieb D. Epidemiology of obstructive sleep apnea: A population health perspective. Am J Respir Crit Care Med. 2002;165:1217-1239.

27. Schutte-Rodin S, Broch L, Buysse D, Dorsey C, Sateia M. Clinical guideline for the evaluation and management of chronic insomnia in adults. J Clin Sleep Med. 2008;4(5):487-504.

28. Ohayon M. Epidemiology of insomnia: What we know and what we still need to learn. Sleep Med Rev. 2002;6(2):97-111.

29. Gunaratnam K, Taylor B, Curtis B, Cistulli P. Obstructive sleep apnea and periodontitis: A novel association? Sleep Breath. 2009;13(3):233-239. 
30. Giles TL, Lasserson TJ, Smith BH, White J, Wright J, Cates CJ. Continuous positive airways pressure for obstructive sleep apnea in adults. Cochrane Database Syst Rev. 2006;(3)(3):CD001106.

31. Barewal RM, Hagen CC. Management of snoring and obstructive sleep apnea with mandibular repositioning appliances: A prosthodontic approach. Dent Clin North Am. 2014;58(1):159-180.

32. Aarab G, Lobbezoo F, Hamburger HL, Naeije M. Oral appliance therapy versus nasal continuous positive airway pressure in obstructive sleep apnea: A randomized, placebocontrolled trial. Respiration. 2011;81(5):411-419.

33. Holley A., Lettieri C, Shah A. Efficacy of an adjustable oral appliance and comparison with continuous positive airway pressure for the treatment of obstructive sleep apnea syndrome. Chest. 2011;140(6):1511-1516.

34. Phillips CL, Grunstein RR, Darendeliler MA, et al. Health outcomes of continuous positive airway pressure versus oral appliance treatment for obstructive sleep apnea: A randomized controlled trial. Am J Respir Crit Care Med. 2013;187(8):879-887.

35. Andrén A, Hedberg P, Walker-Engström M, Wahlén P, Tegelberg A. Effects of treatment with oral appliance on 24-h blood pressure in patients with obstructive sleep apnea and hypertension: A randomized clinical trial. Sleep Breath. 2013;17(2):705-712.

36. Marklund M, Verbraecken J, Randerath W. Non-CPAP therapies in obstructive sleep apnea: Mandibular advancement device therapy. Eur Respir J. 2012;39(5):1241-1247.

37. Gagnon Y, Mayer P, Morisson F, Rompre PH, Lavigne GJ. Aggravation of respiratory disturbances by the use of an occlusal splint in apneic patients: A pilot study. Int J Prosthodont. 2004;17(4):447-453.

38. Rosen RC, Rosekind M, Rosevear C, Cole WE, Dement WC. Physician education in sleep and sleep disorders: A national survey of U.S. medical schools. Sleep. 1993;16(3):249-254.

39. Wells ME, Vaughn BV. Sleep technologists educational needs assessment: A survey of polysomnography, electroneurodiagnostic technology, and respiratory therapy education program directors. J Clin Sleep Med. 2013;9(10):1081-1086.

40. Bian H. Knowledge, opinions, and clinical experience of general practice dentists toward obstructive sleep apnea and oral appliances. Sleep Breath. 2004;8(2):85-90.

41. Tsuiki S, Almeida FR, Lowe AA, Inoue Y. Undergraduate dental education on oral appliance therapy for obstructive sleep apnea at the University of British Columbia. Sleep Biol Rhythms. 2007;5(4):294-299. 
42. American dental association At: http://www.ada.org/sections/professionalResources/ pdfs/survey_allied.pdf. Updated 2012. Accessed: 10/28, 2013.

43. American Dental Hygienists' Association Division of Education. At:

http://www.adha.org/education-careers. Updated 2012. Accessed: 11/04, 2013.

44. Dehaitem MJ, Ridley K, Kerschbaum WE, Inglehart MR. Dental hygiene education about patients with special needs: A survey of U.S. programs. J Dent Educ. 2008;72(9):1010-1019.

45. Navickis MA, Bray KK, Overman PR, Emmons M, Hessel RF, Cowman SE. Examining clinical assessment practices in U.S. dental hygiene programs. J Dent Educ. 2010;74(3):297-310.

46. DeBate RD, Shuman D, Tedesco LA. Eating disorders in the oral health curriculum. $J$ Dent Educ. 2007;71(5):655-663.

47. Miller PM, Ravenel MC, Mauldin MP, Sulkowski S, Lowndes A, Thomas SE. An online alcohol and oral health curriculum for dental students. J Dent Educ. 2014;78(1):16-23. 